\section{The s(p)elling of apo(p)tosis}

SIR - The recent correspondence ${ }^{1}$ about the correct pronunciation of apoptosis prompted me to consider why this subject is so appealing. Thus, although apoptosis is undoubtedly of considerable importance, there is an increasing tendency to claim that it is involved in many cases of cell death where the evidence for its actual involvement is minimal. For example, the protein encoded by one of the two potential candidate genes claimed by different groups to be mutated in spinal muscular atrophy was recently named 'apoptosis inhibitory protein' on the basis of a minimal homology to baculoviral apoptosis inhibitory proteins and the claim that the morphology of dying cells in the disease was consistent with apoptosis ${ }^{2}$. Similarly, it is often claimed (especially in grant requests) that Alzheimer's disease involves apoptotic death, although in fact it now seems more likely that such death is necrotic ${ }^{3}$.

Undoubtedly a major initial appeal of the apoptotic concept was the notion that it could be inhibited with protein synthesis inhibitors, leading to the exciting concept of an active suicide pathway requiring de novo protein synthesis (see for example ref. 4). Yet it now appears that in most cases the death pathway is constitutively primed and needs to be actively inhibited $^{5}$. Thus a combination of a protein kinase inhibitor (staurosporine) and a protein synthesis inhibitor (cycloheximide) produces apoptotic death in most cell types. Had this experiment been performed in the early days of the apoptotic concept, it might have been regarded as akin to the statement that a person dies if shot in the head and heart simultaneously!

There is, of course, no doubt that apoptosis is vital in many systems. Yet our enthusiasm for this concept should not make us believe that it can explain all death phenomena particularly in human disease. In all cases, clear evidence will be required that apoptosis is actually occurring. We should concentrate on acquiring this evidence rather than worrying about how the term itself should be pronounced. David S. Latchman

University College London Medical School, Department of Molecular Pathology, 46 Cleveland Street, London W1P 6DB, UK

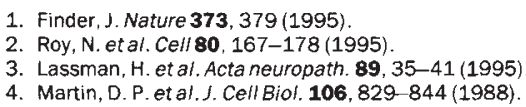

SIR - I suggest that you ask the Greeks about the proper pronunciation of the word apoptosis. The word $\alpha \pi o ́ \pi \tau \varpi \sigma \iota \zeta$ is still in use in the modern Greek language and its second $\mathrm{p}$ is very much pronounced just like the $p$ in other Greek words adopted by Western languages, such as helicopter, Archaeopteryx, optic, apterous, aptotic, symptomatic and so on.

\section{J. G. Georgatsos}

Laboratory of Biochemistry,

University of Thessaloniki, Greece

SIR - For good measure, helicopter is herikoputa in Japanese.

\section{G. De Mey}

Afrikalaan 11

B-3080 Tervuren, Belgium

\section{Necessary brain}

SIR - John Godfrey's well-reasoned Commentary ${ }^{1}$ neglected to elaborate the argument relating to the central role of the brain in judging the ontogeny of a human $^{2}$. That neglect provided the openings for the barrage of opposing statements supporting the position of the Roman Catholic church on the time of appearance of a human being ${ }^{3-7}$

One must distinguish between "human life" and the "life of a human person". Without a functioning brain there is no human person. Indeed, when the brain dies the person is regarded, legally and morally, as dead, even though the rest of this unique human body may still be alive and healthy. In fact, the heart, liver, kidneys and so on may legally be removed from this living body for transplantation into another. Clearly, a uniquely individual human body without a functional brain is regarded as human living tissues but not as a person. I believe even the Catholic church agrees with this view and policy.

At conception, regardless of the precise definition employed, there is no brain at all. When does the brain appear and develop to a stage one may regard as having the characteristics or qualities of a human person? The achievement of such characteristics is not a sudden, all-or-none phenomenon and may be regarded as developing in progressively meaningful stages. But there is surely a minimum stage below which the person could not begin to appear. This minimum stage would require not merely the appearance and organization of the neurons, especially in the forebrain, but also the development of synaptic and functional interconnections, to a level at which the brain exhibits physiological arousal, EEG responsiveness to a sensory input. This state is not achieved until well into the second trimester of fetal life and perhaps even later.

Before the achievement of a brain with at least the minimum characteristics for human personhood, the fetus is best regarded as living and developing human tissue, no more a person than is an adult human individual whose brain is dead. The argument that there is a human person present before the minimum stage of brain (or even at conception), would have to be based on a religious or philosophical belief that the embryo or fetus is already a person even when there is no suitable brain.

\section{Benjamin Libet}

Department of Physiology,

University of California, San Francisco,

San Francisco,

California 94143-0444, USA

2. Libet, B. Science 213, 213 (1981)

3. Jones, D. A. \& Haynie, D. T. Nature 373, 652 (1995)

4. Herranz, G. Nature 373,652 (1995)

5. Jarmulowicz, M. Nature 373, 652 (1995)

6. Johnson, W.V. Nature 374, 10 (1995)

7. Montuenga, L. M. Nature 374, 10 (1995)

\section{Authors' rights}

SIR - I have been asked to contribute a chapter to a book, and I am being asked to sign a contract with the publisher. It is a fairly standard contract for this sort of task: I agree to provide a chapter to their specifications, with illustrations, by a date they decide; I agree to obtain written permission to reproduce figures and tables from other published works; I agree to review copy-edited text and to review and correct proofs promptly (but not further revise them). Furthermore, I am asked to assign to the publisher all copyright in the material, both text and figures. (Even though I may spend hours drawing these figures on my personal computer, I shall have to ask permission from the publisher if I want to use them in another article.)

What do I get in return for all this? Almost nothing financial. (In this particular case, 5 per cent of receipts will be divided between about 60 authors.) Again, in this particular case I am only offered one copy of the book between myself and as many co-authors as I decide to co-opt. What does the publisher get? The text of a book that will no doubt bring in a nice sum of money over the years. What assurance do I get even that my article will be published? None. I am sure other authors will have shared my experience of learning some years after sweating over a chapter that the publisher has decided not to go ahead with the project.

Why do scientists put up with this? Does it reflect the low self-esteem in which we hold ourselves? Do we see ourselves as dogsbodies, working only for other people's gain? I have had enough - I may write the chapter, but I am not going to sign this contract. I hope other scientists will join me in beginning to protest about our exploitation by scientific publishers.

\section{Kelth Frayn}

Radcliffe Infirmary,

Oxford OX2 6HE, UK 